Article

\title{
What Are Your Children Watching? Teacher's Evaluation of the Educational, Emotional, Behavioral, Psychological, Physical \& Religious impacts of Cartoons on the School Going Children
}

Syed Hassan Raza* (Corresponding author)

* PhD Scholar at School of Multimedia Technology \& Communication, Universiti Utara, 06010 Sintok, Kedah, Malaysia / Lecturer in Department of Mass Communication, Bahauddin Zakariya

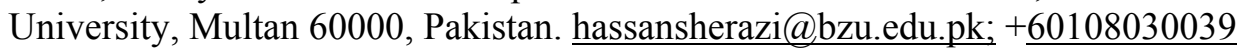

Sajid Mahmood Awan

Senior Research Fellow at National Institute of Historical and Cultural Research Quaid-i-Azam University, Islamabad 45320, Pakistan. smawan2222@gmail.com

Sarfraz Nawaz Gondal

Department of Communication Studies, Bahauddin Zakariya University, Multan 60000, Pakistan

\begin{abstract}
Cartoons in the era of digital media are among the most prevalent medium of entertainment for the children, parents also encourage them to view such contents to engage the children which make an area need to be explained exhaustively by adopting new approaches. There are lot of studies in the past conducted to explain the impacts of the cartoons on the children however, it is remarkable fact that there is lack of the studies in the literature which directly address the observation about the above mentioned impacts in view of the teacher's. This study deals with the educational, emotional, behavioral and Religious etc. impacts of cartoons on kids in view of teachers of the primary schools as they are considered as the one who can observer these impacts in a profound way. of the of Multan. Different areas of impacts have been analyzed in this study by using survey technique and analysis is conducted and presented in the teacher's views in this study to examine what they feel that how cartoons are effecting the personalities of the children.
\end{abstract}

Keywords: educational impacts; emotional impacts; behavioral impacts; psychological impacts; physical impacts; religious impacts 


\section{Introduction}

This is all about the present time the social structure of families, electronic media are thoroughly incorporated with the foundation of life, with television, movies, videos, music, video games, and computers central (Klinger, 2007; Westjohn, Singh, \& Magnusson, 2012) to both occupation and play. Newest studies of opinion that even the youngest kids are using an extensive range of screen media (Cooper-Chen, 2012; Zhang, 2006), a lot of at senior levels than recommended by child development professionals. Therefore, there are swiftly intensifying marketplaces for early childhood television programming, computer software for toddlers, and video series for children. Cartoon programs are above all in shaping up the behavior and actions of the children in many dimensions including the religious concepts. Therefore, the cartoons in the current times are amongst the utmost general medium for entertaining the children, many innovative ideas are learned by the children through watching cartoons, at the same time the exposure of the cartoons to the children also have impacts on the religious thoughts as well.

Additionally, the cartoons have much value in personality building of the children especially in early age so that it can impact the child ideas concepts about their actions including cultural and religious one. Children start watching cartoons at the age of two years and form the age of 2 to 11 year they spent more time in front of television watching their favorite content then the time they have passed in school (Rosset et al., 2010). Thus, the cartoons programs are much effective the school lessons. Sometime children imagine themselves like cartoon characters. This is due to their likeness and interest as it is nature of the children that with whom they get impressed they adopt some features of that personality. Similarly, children also adopt some habits from cartoons characters and when they pick their characteristics they become part of their personality. Therefore, there is need to examine that now, this new impacts of the cartoons are positive or negative and how they adopt these ideas in this ordinary life.

The present study explains the phenomena in the view of their teachers that how they act on the basis of the characters presented in the cartoons, and really they start to act accordingly to get impress from those characters. Consequently, the study intends to know about the areas of their routine educational life children get ideas or the content, thus the impact of cartoon characters leave in the personality of children. This research is aimed to find out the effects of cartoons character on the personality and the dealing of the children with their friends in view of their teachers.

\subsection{Objectives of the Study}

1. To determine the educational impacts on kids through cartoon characters

2. To observe the psychological changes in the personality of kids through watching cartoons.

3. To determine the impacts of the cartoon viewing on the behavior of students in school.

4. To identify the impacts of cartoons on children about their religious understanding about religious ideas, practices and heroes.

5. This study will helpful for incoming researcher 


\section{Literature Review}

Amongst one of the preliminary study, Gerbner, Gross, Morgan, \& Signorielli, (1986) studied 138 university students, and found that memories of fear-provoking media images sustained to upset a noteworthy amount of participant's years later. Over 90 per cent reported they continued to practice scare belongings from images they viewed as children, ranging from sleep instability to unswerving prevention of convinced situations. The consequences of an additional study demonstrate that in the USA an average of 20-25 aggressive acts are revealed in children's television programs each hour. A considerable connection was established between the amount of time spent watching television during teenage years, with its revelation to aggression, and the possibility of succeeding disruptive activities, such as aggressive violence, assault or physical clashes resulting in damage, and shoplifting. $61 \%$ of children's television programs contain violence and only $4 \%$ have an anti-violence theme. In programs with violence only $16 \%$ showed long-term consequences, $45 \%$ of the offenders went unpunished, $71 \%$ of offenders showed no remorse, $42 \%$ of the violence was associated with humor, and lethal violence was shown in $54 \%$ of programs.

The findings of the previous studies show the association between screen violence and road violence has been studied ever since the early days of television - some say over 3,000 studies in the past four decades (Forge \& Phemister, 1987; Gadow, Sprafkin, \& Ficarrotto, 1987; Sprafkin, Gadow, \& Grayson, 1988). While it is too simplistic and impossible to "confirm" that the media portrayals reasons of violence in reality (Sprafkin et al., 1988), there are many more studies that explore how media violence is perceived by viewers or internalized in attitudes and/or behaviors. In one interesting study, social science researchers have evolved and identified six different and distinct characteristics of "violence" in film and then explored how viewers of different ages and stages of maturity, responded (Forge \& Phemister, 1987; Gadow et al., 1987; Klavir \& Gorodetsky, 2001). The ultimate findings depict that the aggression telecasted by the cartoon movies is absorbed by the children and then they implement that violence in their daily life.

In the early 90s, the federal broadcast regulator, the Canadian Radio-television and Telecommunications Commission (CRTC), began consultations on the issues relating to television violence with the broadcasting, cable and program production industries, as well as public health professionals, educators, policy-makers and consumer groups (Canadian Radio-television and Telecommunications Commission, 2014). At the same time, following several tragic "flashpoints," a petition against media violence, signed by 1.3 million Canadians, was presented to the Prime Minister. The industry-based Action Group on Violence on Television (AGVOT) was formed at this symposium and soon after, the Canadian Association of Broadcasters (CAB) filed with the CRTC a revised, strengthened voluntary code on violence in broadcasting. The violence shown by the T.V programs is creating aggressive behaviors among the viewers and the most affected part of society is children.

Furthermore, it was also explored that the children in the early age was not the regular users of TV. They dropped in on another person watching TV and their most favorite content is cartoon; three-year-old kids watch cartoons about 45 minutes in a day. But from the age of four to ten year they increase this time more than two hours. At the age of 11 to 12 year this time increase suddenly 3 to 4 hours in a day (DiFranza et al., 1991; Rosset et al., 2008). From the age of 3 to 11 year children spent more time in front of TV then school, because they want to watch cartoons than any other activity. 
Moreover, the main characters of children programs were animated characters, or puppets like Duck, hound, doody, Rin tin etc (Grelotti et al., 2005; Yu, Cheng, \& Tao, 2012; Yu, Liu, Tao, \& Seah, 2012). However, sometime children themselves feel as a positive character of the program as the programs and contents presented in a humorous and storytelling manners. The stories were uncomplicated and easy which create humor, excitement and adventure for children. Such programs dominate children early school years and soon two new types of programs introduced which are crimes based and situational comedy. As the children enter in adult age on other type of program enter in adult age on other type of programs become important in their life which is popular music (Iwata, Matsuda, \& Morihara, 1999; Xi \& Rong, 2009). Nevertheless, in all categories of cartoons programs children want to see comedy and excitement in the shape of characters of cartoons (Hassan \& Daniyal, 2013). Consequently, due these interesting features in the cartoons the children divert their imaginations towards these cartoons and this is a potential factor that they may adopt many features and characteristics in their ordinary life by practicing them, therefore we presented following hypothesis to capture the opinion of the teachers to know about their evaluation about the impacts of the cartoons on the children.

\subsection{Hypothesis}

1. Cause of cartoon watching bears effects on the education of kids.

2. Cause of cartoon watching bears psychological effects on kids such effects are Innovation, Intelligence and Toleration

\section{Research Design}

\subsection{Method}

This particular study chooses survey method as a research design and quantitative method of data collection is used. Quantitative data is help full to get the information in the primary data (Prendergast, Gerard, 2002) therefore; the current study is intended to know the view of the mentors directly that how they observe and evaluate the effects of the cartoons on the kids to obtain basic data for hypothesis testing, researcher used survey method and a questionnaire was formulated for this purpose. The structured questionnaire comprises of mostly closed ended questions with a few questions having an option of other with specification has been used to get the basic information has been used to get the basic information and opinion of sample. The questionnaire has been used as a tool of data collection.

\subsection{Participants}

The survey uses both descriptive and analytical methods to address the stated research aims descriptive surveys or studies also serve as direct sources of valuable knowledge concerning human behavior. Descriptive studies are helpful for planning various educational programs. This study also benefits from this method. In this study the researcher selects the teachers of the primary school of the Multan as the universe of the study. "The name for the large general group of many cases from which a researcher draws a sample and which is usually stated in theoretical terms". The purposive sample consists of 5 primary school of Multan and 100 teachers of these schools are selected. Respondents which are statistically appropriate sample size. "A smaller set of case a researcher selects from a larger pool and generalizes to the population". Sample is selected from five primary schools in Multan every schools gets $20 \%$ representation in the sample. It is limitation of 
the data that most of the location are very far so that researcher used personal relations without any pay.

\section{Data Analysis}

Quantitative techniques have been used to analyze information gathered in the survey. A description of the gathered data set is presented both in tabulated and chart form. As mentioned in section researcher has used the survey method with the help of comprehensive questionnaire. The purposive sample consists of 100 respondents which is statically appropriate sample size. As reflected from some of observations below, the sample is characterized with a number of features which are a very close, representation of the population.

As presented in the figure 1 it can be clarified that spelling in the personality building of kids by cartoon characters has more impact as $52 \%$ of sample of this view and general knowledge is second more impact as $32 \%$ of sample of this view which has been seen in the result of study and vocabulary has least impact (16\%). Overall result shows that the impact of spelling is more than other educational impact.

As shown in the figure 2 it can be illustrated that excitement in the personality building of kids by cartoon characters has more impact as $56 \%$ of sample of this view and aggression is second more impact as $32 \%$ of sample of this view which has been seen in the result of study and sadness has least impact (12\%). Overall result shows that the impact of excitement is more than other educational impact.

As revealed in the figure 3 it can be demonstrated that obedient in the personality building of kids by cartoon characters has more impact as $52 \%$ of sample of this view and politeness is second more impact as $36 \%$ of sample of this view which has been seen in the result of study and rigidness has least impact (12\%). Overall result shows that the impact of obedient is more than other educational impact.

As displayed in the figure 4 it can be explained that intelligence in the personality building of kids by cartoon characters has more impact as $44 \%$ of sample of this view and innovation is second more impact as $32 \%$ of sample of this view which has been seen in the result of study and toleration has least impact (24\%). Overall result shows that the impact of intelligence is more than other educational impact.

As presented in the figure 5 it can be illustrated that healthy ness in the personality building of kids by cartoon characters has more impact as $64 \%$ of sample of this view and lazy ness is second more impact as $28 \%$ of sample of this view which has been seen in the result of study and weakness has least impact (8\%). Overall result shows that the impact of healthy ness is more than other educational impact.

As shown in the figure 6 it can be illustrated that imagination in the personality building of kids by cartoon characters has more impact as $48 \%$ of sample of this view and daydreaming is second more impact as $32 \%$ of sample of this view which has been seen in the result of study and fantasy has least impact (20\%). Overall result shows that the impact of imagination is more than other educational impact.

As revealed in the figure 7 it can be illustrated that emotional impact in the personality building of kids through cartoon characters has more important impact as 
$19.0 \%$ of sample of this view and Religious impact is second more important impact as $18.2 \%$ of sample of this view which has been seen in the result of study and the third more important impact is emotional impact is $16.7 \%$ and fourth more important impact is physical impact is $16.3 \%$ and the fifth more important impact is psychological impact is $15.3 \%$ and the least important impact is behavioral impact has $(14.5 \%)$. Overall result shows that the educational and religious impacts are more than other impacts.

\section{Discussion \& Conclusion}

The results of the study are demonstrating that spelling in the personality building of kids by cartoon characters has more impact as $52 \%$ of sample of this view and general knowledge is second more impact as $32 \%$ of sample of this view which has been seen in the result of study in the view of the teachers. Whereas, vocabulary has least impact $(16 \%)$. It is observed that excitement in the personality building of kids by cartoon characters has more impact as $56 \%$ of sample of this view and aggression is second more impact as $32 \%$ of sample of this view which has been seen in the result of study and sadness has least impact $(12 \%)$. The results indicate that obedient in the personality building of kids by cartoon characters has more impact as $52 \%$ of sample of this view. Moreover, politeness is second more impact as $36 \%$ of sample of this view which has been seen in the result of study and rigidness has least impact (12\%). The study also indicates (see figure no 4) that intelligence in the personality building of kids by cartoon characters has more impact as $44 \%$ of sample of this view and innovation is second more impact as $32 \%$ of sample of this view which has been seen in the result of study and toleration has least impact (24\%). The findings (see figure no 5) illustrates that healthy ness in the personality building of kids by cartoon characters has more impact as $64 \%$ of sample of this view and lazy ness is second more impact as $28 \%$ of sample of this view which has been seen in the result of study and weakness has least impact (8\%) furthermore, (see figure no 6) indicates that imagination in the personality building of kids by cartoon characters has more impact as $48 \%$ of sample of this view and daydreaming is second more impact as $32 \%$ of sample of this view which has been seen in the result of study and fantasy has least impact (20\%). It is illustrated that the educational that emotional impact in the personality building of kids by cartoon characters has more important impact as $19.0 \%$ of sample of this view and Religious impact is second more important impact as $18.2 \%$ of sample of this view which has been seen in the result of study and the third more important impact is emotional impact is $16.7 \%$ and fourth more important impact is physical impact is $16.3 \%$ and the fifth more important impact is psychological impact is $15.3 \%$. And the least important impact is behavioral impact has $(14.5 \%)$.

The result of this study indicates that there are potential impacts on the children daily life and specifically on the educational life of the children as it is reflected in the evaluation based on the teachers of the school going children, thus, it can be concluded that children are watching cartoons and getting impacts ranging from the emotional to the physical. However, the impact on the educational and religious ideas are seen higher than the others one in the evaluation of the teachers as we asked them to about their evaluation about the impacts of cartoon and its characters on the basic ideas, understandings and heroes of the children. Therefore, it suggests that there is need for the parents to rethink that rather they are exposing their children to such contents in the cartoons which is misleading their children in the religious matters. Hence, it is still an area where more research can be conducted by adopting different perspectives to understand this phenomena current study focuses on the opinions of the teachers and concluded that there are impacts on the cartoons on the different aspects of the children's personality. 


\section{References}

Canadian Radio-television and Telecommunications Commission. (2014). Canadian Radiotelevision and Telecommunications Commission.

Cooper-Chen, A. (2012). Cartoon planet: the cross-cultural acceptance of Japanese animation. Asian Journal of Communication, 22(1), 44-57.

DiFranza, J. R., Richards, J. W., Paulman, P. M., Wolf-Gillespie, N., Fletcher, C., Jaffe, R. D., \& Murray, D. (1991). RJR Nabisco's cartoon camel promotes camel cigarettes to children. Jama, 266(22), 3149-3153. http://doi.org/10.1001/jama.266.22.3149

Forge, K. L., \& Phemister, S. (1987). The effect of prosocial cartoons on preschool children. Child Study Journal.

Gadow, K. D., Sprafkin, J., \& Ficarrotto, T. J. (1987). Effects of viewing aggression-laden cartoons on preschool-aged emotionally disturbed children. Child Psychiatry \& Human Development, 17(4), 257-274. http://doi.org/10.1007/BF00706450

Gerbner, G., Gross, L., Morgan, M., \& Signorielli, N. (1986). Living with Television : The Dynamics of the CuItivation Process. Perspectives on Media Effects, 17-40. http://doi.org/10.1007/s13398-014-0173-7.2

Grelotti, D. J., Klin, A. J., Gauthier, I., Skudlarski, P., Cohen, D. J., Gore, J. C., ... Schultz, R. T. (2005). fMRI activation of the fusiform gyrus and amygdala to cartoon characters but not to faces in a boy with autism. Neuropsychologia, 43(3), 373-385. http://doi.org/10.1016/j.neuropsychologia.2004.06.015

Hassan, A., \& Daniyal, M. (2013). Cartoon Network and its Impact on Behavior of School Going Children: A Case Study of Bahawalpur, Pakistan. International Journal of Management Economics and Social Sciences, 2(1), 6-11.

Iwata, S., Matsuda, T., \& Morihara, T. (1999). Human-machine interface using humanoid cartoon character. Fujitsu Scientific and Technical Journal, 35(2), 165-173.

Klavir, R., \& Gorodetsky, M. (2001). The processing of analogous problems in the verbal and visual-humorous (cartoons) modalities by gifted/average children. Gifted Child Quarterly, 45(3), 205-215. http://doi.org/10.1177/001698620104500305

Klinger, L. J. (2007). What are your children watching? a DPICS-II analysis of parent-child interactions in television cartoons. Dissertation Abstracts International: Section B: The Sciences and Engineering, 67.

Prendergast, Gerard, B. H. y I. P. (2002). A Hong Kong view of offensive advertising. Journal of Marketing Communications, 8(3), 165-177.

Rosset, D. B., Rondan, C., Da Fonseca, D., Santos, A., Assouline, B., \& Deruelle, C. (2008). Typical emotion processing for cartoon but not for real faces in children with autistic spectrum disorders. Journal of Autism and Developmental Disorders, 38(5), 919-925. http://doi.org/10.1007/s10803-007-0465-2

Rosset, D. B., Santos, A., Da Fonseca, D., Poinso, F., O’Connor, K., \& Deruelle, C. (2010). Do children perceive features of real and cartoon faces in the same way? Evidence from typical development and autism. Journal of Clinical and Experimental Neuropsychology, 32(2), 212-218. http://doi.org/10.1080/13803390902971123

Sprafkin, J., Gadow, K. D., \& Grayson, P. (1988). Effects of cartoons on emotionally disturbed children's social behavior in school settings. Journal of Child Psychology and Psychiatry, and Allied Disciplines, 29(1), 91-99. http://doi.org/10.1111/j.14697610.1988.tb00692.x 
Westjohn, S. a, Singh, N., \& Magnusson, P. (2012). Responsiveness to Global and Local Consumer Culture Positioning: A Personality and Collective Identity Perspective. Journal of International Marketing, 20(1), 58-73.

Xi, J., \& Rong, Z. (2009). A research on the design of the cartoon toys based on the analysis of the characters in the cartoon. In Proceeding 2009 IEEE 10th International Conference on Computer-Aided Industrial Design and Conceptual Design: EBusiness, Creative Design, Manufacturing - CAID and CD'2009 (pp. 2193-2196). http://doi.org/10.1109/CAIDCD.2009.5375135

Yu, J., Cheng, J., \& Tao, D. (2012). Interactive cartoon reusing by transfer learning. Signal Processing, 92(9), 2147-2158. http://doi.org/10.1016/j.sigpro.2012.01.028

Yu, J., Liu, D., Tao, D., \& Seah, H. S. (2012). On combining multiple features for cartoon character retrieval and clip synthesis. IEEE Transactions on Systems, Man, and Cybernetics, Part B: Cybernetics, 42(5), 1413-1427. http://doi.org/10.1109/TSMCB.2012.2192108

Zhang, Y. B. (2006). The Portrayal of Older Adults in Advertising: A Cross-National Review. Journal of Language and Social Psychology, 25(3), 264-282.

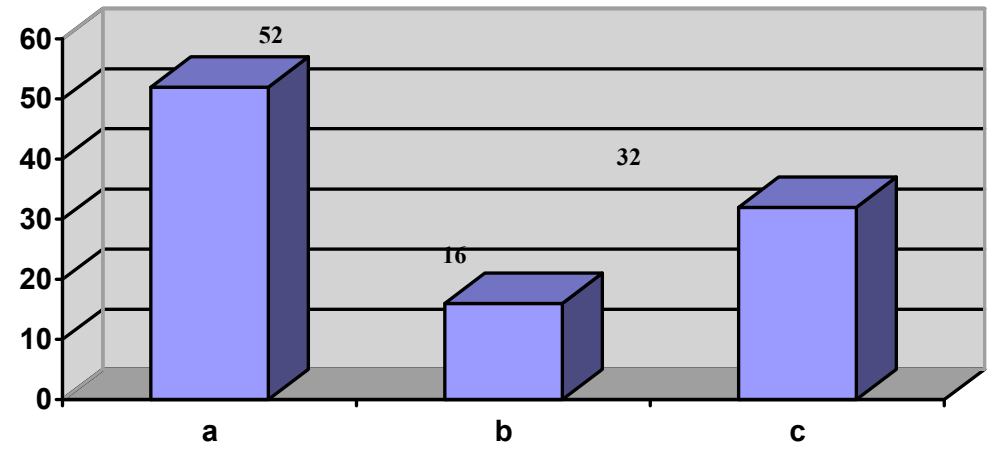

$\square$.

Figure No. 1: $\quad$ Educational Impact in Evaluation of Teachers
a. $\quad$ Spelling
b. Vocabulary
c. General knowledge

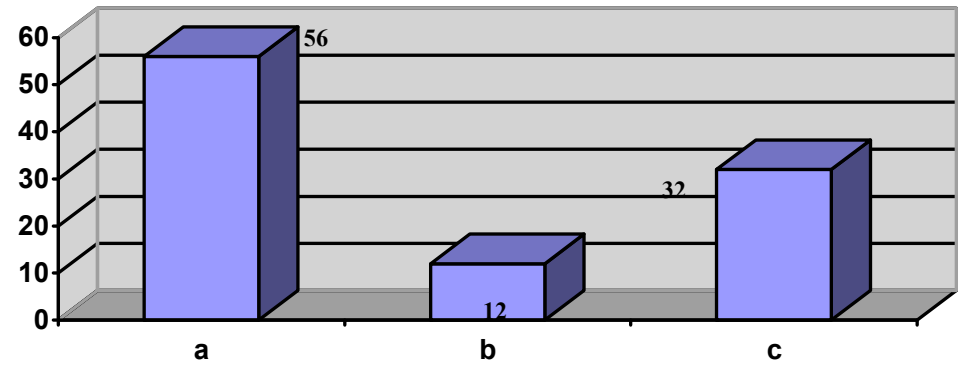

Figure No. 2: Emotional Impact in Evaluation of Teachers

a. Excitement 
b. Sadness

c. Aggression

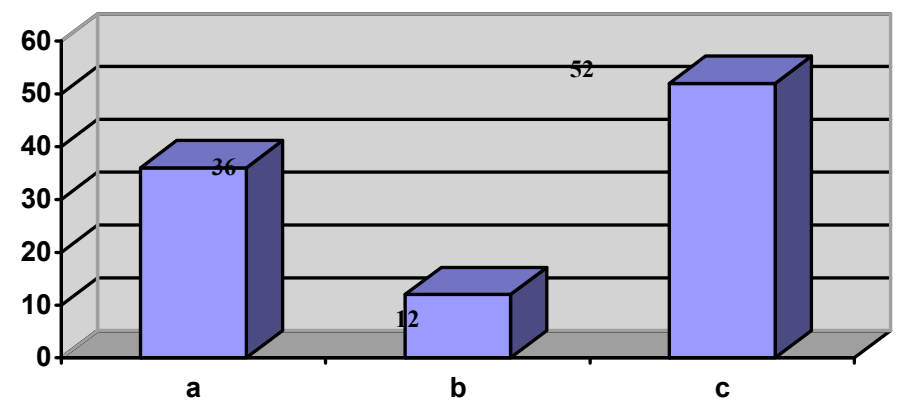

$\square$.

Figure No. 3: Behavioral Impact in Evaluation of Teachers
a. Polite
b. Rigid
c. Obedient

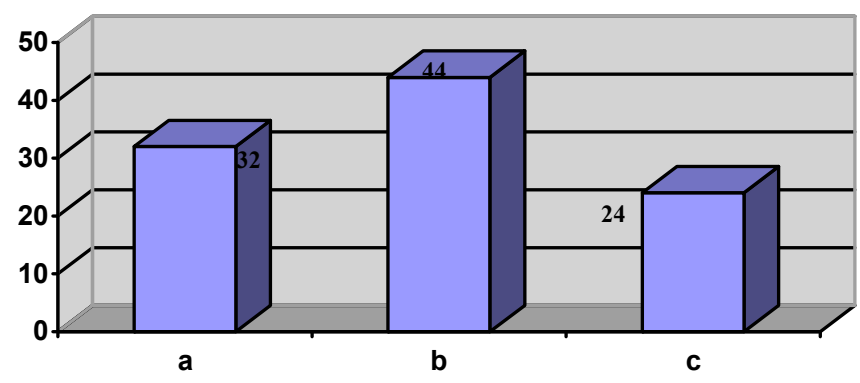

口.

Figure No. 4: Psychological Impact in Evaluation of Teachers
a. Innovation
b. Intelligence
c. Toleration

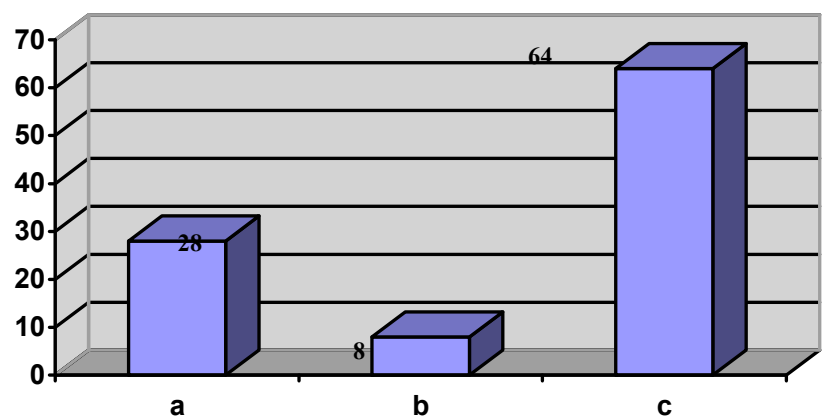

Figure No. 5: Physical Impact in Evaluation of Teachers

a. Lazy 

b. Week
c. Healthy

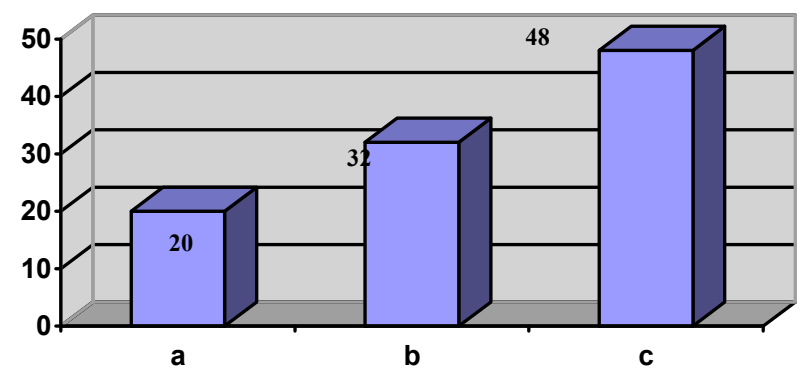

Figure No. 6: Religious Impact in Evaluation of Teachers
a. Ideas/ concepts
b. Basic practices
c. Heroes

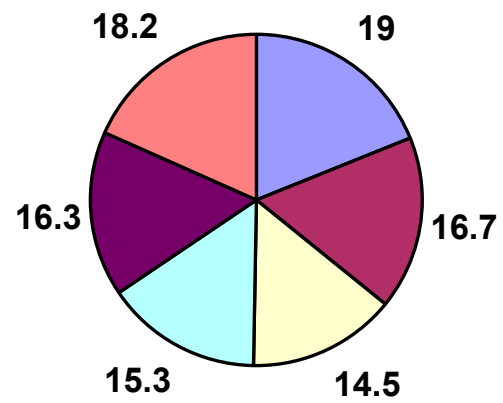

Figure No. 7: Over all Impacts by Teacher
a. Educational
b. Emotional
c. Behavioral
d. Psychological
e. Physical
f. Religious access article distributed under the terms and conditions of the Creative Commons by Attribution (CC-BY) license (http://creativecommons.org/licenses/by/4.0/). 